\title{
A importância das ações sociais empresariais nas decisões de compra dos consumidores
}

\author{
The importance of corporate social actions in \\ consumers purchase decisions
}

\author{
Braulio Oliveira ${ }^{1}$ \\ Maria Aparecida Gouvêa²
}

\begin{abstract}
Resumo: Atualmente muitas empresas vêm realizando ações de cunhos sociais sob a crença de que a sociedade atribui a ela um papel que vai além do seu comportamento ético e legal, e de que isso possa ser valorizado pelos seus públicos-alvo, e até se reverter em algum tipo de preferência por ela e seus produtos. Assim, este trabalho teve por objetivo verificar se a Responsabilidade Social Empresarial é importante nas decisões de compra dos consumidores, e o quão importante ela é frente a outros fatores. Para tanto, além da revisão bibliográfica dos assuntos pertinentes ao tema, foi realizada uma pesquisa de campo em duas etapas: uma exploratória, de natureza qualitativa, a fim de se levantar os fatores relevantes para a decisão de compra; e outra conclusiva descritiva, de natureza quantitativa, com amostragem probabilística, pós-graduandos de uma universidade paulista. Os resultados apontam que as ações sociais são menos importantes do que outros fatores considerados na pesquisa para as decisões de compra. Apontam, também, que apenas uma pequena parcela da população considerada conhece as ações sociais às quais os produtos e empresas considerados estão vinculados. Tais resultados suscitam uma reflexão sobre o retorno que efetivamente as empresas têm em relação a essas ações, bem como à divulgação delas.
\end{abstract}

Palavras-chave: Ações sociais empresariais. Decisão de compra. Comportamento do consumidor.

\begin{abstract}
Currently, many companies have been developing social actions considering that society assigns them a role that goes beyond ethical and legal behavior, which may be valued by their target audiences and may even help them regain lost preference for their products. This work aimed to verify the importance of those actions in purchasing decisions of consumers. Therefore, in addition to the literature review of issues relevant to the topic, we conducted a descriptive conclusive research, with probability sampling, with 60 graduate students of a university located in São Paulo state, between the months of June and July 2009. The results show that social actions are less important than other factors considered in the investigation of purchasing decision factors. The findings also indicate that only a small portion of the population was aware of the social actions to which the companies and their products were linked. These results deserve further reflection on the return that companies actually have from those actions, as well as the dissemination of corporate social action projects.
\end{abstract}

Keywords: Corporate social actions. Purchase decision. Consumer behavior.

\section{Introdução}

O desenvolvimento da sociedade com a contribuição de ações realizadas ou patrocinadas por empresas parece ser uma tendência irreversível, uma vez que se pode observar essas iniciativas como cada vez mais comuns.

Para fins do presente trabalho, consideraram-se ações sociais as iniciativas e os programas realizados ou apoiados por empresas, que visam à melhoria da qualidade de vida dos cidadãos que compõem uma comunidade e que não se restringem aos seus funcionários e colaboradores, e como causa social, um tema ou área de interesse público para a qual uma empresa contribui ou a qual apoia.

Muito embora a realização ou o patrocínio de ações sociais por empresas possam ter um cunho meramente filantrópico, sem objetivos de retornos em termos de negócios, este trabalho tem o objetivo de explorar elementos baseados na relação investimento-retorno.

\footnotetext{
${ }^{1}$ Programa de Pós-graduação Stricto Sensu em Administração, Fundação Educacional Inaciana - FEI, Rua Tamandaré, 688, Liberdade, São Paulo - SP, CEP 01525-000, E-mail: braulio@usp.br

${ }^{2}$ Departamento de Administração, Faculdade de Economia e Administração da Universidade de São Paulo - FEA/USP,

Av. Prof. Luciano Gualberto, 908, Cidade Universitária, São Paulo - SP, CEP 05508-010
}

Recebido em 14/1/2010 — Aceito em 15/10/2010

Suporte financeiro: Nenhum. 
De acordo com Jones, Comfort e Hilliard (2007), a responsabilidade social empresarial (RSE) diz respeito à incorporação de questões econômicas, sociais e ambientais nas estratégias de negócios.

Para Jones, Comfort e Hilliard (2007), entre os diversos benefícios apontados como motivadores do exercício da RSE, estão a melhoria do desempenho financeiro e da lucratividade, o aumento do valor de marca e a melhoria do relacionamento com governos e comunidades.

De acordo com Castaldo et al. (2009), a literatura relativa à RSE aponta que os consumidores importam-se com a questão, e que as ações sociais influenciam as suas decisões de compra. No entanto, essas influências, não são comprovadas como fortes pelos estudos empíricos realizados até então, apontando correlações moderadas, embora positivas e, em muitos casos, outros fatores, tanto por parte das empresas, quanto por parte dos consumidores, apresentam-se como mais importantes (CASTALDO et al., 2009).

$\mathrm{O}$ investimento das empresas em ações de responsabilidade social pressupõe que o mercado pressiona e valoriza atitudes e comportamentos que vão além da oferta de produtos de boa qualidade a baixo preço (MARIN; RUIZ; RUBIO, 2009). Portanto, do ponto de vista da gestão empresarial, os recursos destinados às ações sociais devem produzir resultados diretos ou indiretos que contribuam para a sua longevidade - $\mathrm{o}$ que evidentemente não desmerece tais ações (VALOR, 2008).

Assim, é evidente que essas ações devem ser conhecidas e valorizadas pelos consumidores, de forma que esses possam propiciar uma contrapartida às empresas patrocinadoras, quando da decisão de compra.

Mas um estudo realizado por Valor (2008) concluiu que os consumidores não premiam as empresas responsáveis socialmente com o ato da compra, uma vez que questões motivacionais, cognitivas e comportamentais constituem-se obstáculos para tal. (VALOR, 2008).

Marin, Ruiz e Rubio (2009) corroboram essa ideia ao afirmarem que, embora a responsabilidade social seja uma variável apontada pelos consumidores como importante para que se desenvolva fidelização, critérios tradicionais como preço, qualidade e conhecimento da marca ainda apresentam-se como mais importantes para a decisão de compra, demonstrando que as escolhas são mais pessoais do que sociais.

Não obstante haja divergências quanto ao retorno que efetivamente as empresas obtêm com a realização ou o patrocínio de ações sociais, pode-se assumir que os possíveis benefícios apresentam-se como oportunidades a elas, à medida que os consumidores priorizem produtos e serviços daquelas que forem percebidas como socialmente responsáveis. Assim, uma questão que se coloca é a seguinte: as ações sociais realizadas ou apoiadas por empresas é um fator relevante nas decisões de compra dos consumidores?
Assim, este trabalho teve como objetivo principal detectar a importância que é dada às ações de RSE em termos de contribuição para a decisão de compra dos consumidores. Adicionalmente, como objetivo secundário, buscou-se levantar o nível de conhecimento desses mesmos consumidores sobre as ações realizadas ou patrocinadas pelas empresas e produtos considerados.

Este artigo está dividido em seis partes, incluindo esta introdução. Na segunda parte, aborda-se a RSE; na terceira, o relacionamento do consumidor frente à RSE; na quarta, a metodologia da pesquisa de campo; na quinta, são apresentados e analisados os resultados da pesquisa de campo; por fim, na sexta parte, são apresentadas as conclusões do estudo.

\section{Responsabilidade social empresarial}

O papel das empresas na sociedade há muito vem sendo discutido. Friedman (1970) defendia a ideia de que as empresas possuem tão somente a responsabilidade social de gerarem lucros e serem corretas em termos de legalidade. No entanto, à medida que a sociedade pressiona as empresas a participarem de maneira mais ativa e direta das questões que as afetam, o mero cumprimento dos padrões éticos e legalmente estabelecidos não é suficiente para satisfazê-la.

Portanto, a RSE é resultado do reconhecimento de que as empresas são grandes detentoras de poder financeiro e de que afetam direta ou indiretamente a sociedade (BORGER, 2001). Nesse sentido, a RSE não é uma moda ou um opcional às empresas, pois é resultado da profunda mudança de relacionamento entre as empresas e os seus públicos (LEWIS, 2001).

Assim,

[...] as questões sociais não podem ser consideradas como problemas exclusivos do governo e a omissão das empresas não é uma postura condizente com a liberdade econômica e a desregulamentação e liberalização da economia. (BORGER, 2001).

De acordo com Carroll (1999), a era da RSE teve início com o livro Social Responsibilities of the Businessman, de Bowen (1953), no qual ela era definida como as obrigações desejáveis em termos de objetivos e valores sociais.

Embora haja grande diversidade das atuações das empresas no que tange à responsabilidade social, é possível identificar dois tipos básicos: o primeiro considera as ações como um bem em si mesmas, geradoras de resultados para a população-alvo; o segundo considera essas ações em termos estratégicos de negócio, com vistas à melhoria do desempenho dos produtos e de marcas (FISCHER, 2002; ASHLEY, 2002). 
A RSE é constituída por duas dimensões: a interna, que tem como público seus empregados e seus dependentes, e a externa, que tem como foco a comunidade, por meio de ações sociais voltadas principalmente para as áreas de educação, saúde, assistência social e ecologia (MELO NETO; FROES, 1999).

Ressalte-se que as empresas não devem se desvincular dos seus objetivos econômicos, pois, de fato, também são socialmente responsáveis ao gerar empregos, recolher impostos e gerar riqueza dentro das normas sociais vigentes. No entanto, tais realizações são esperadas das empresas e admitidas como mínimas, devendo empreender ações que extrapolem as suas obrigações para que sejam bem vistas pela sociedade (BORGER, 2001).

Investindo em projetos sociais a empresa assume a sua responsabilidade social e oferece algo em troca ao que por ela foi usurpado da sociedade. (MELO NETO; FROES, 1999).

À parte as discussões relativas às pressões que as empresas recebem e às finalidades que elas possuem na sociedade, fato é que tais movimentos da sociedade colocam-se como oportunidade de negócio àquelas mais arrojadas e que melhor souberem adequar ações aos descontentamentos sociais existentes. Em 1971, Johnson apresentou em seu livro Business in Contemporary Society: framework and issues a RSE como uma estratégia para a maximização dos lucros a longo prazo, visão esta que se constitui em grande estímulo para que as ações desta natureza proliferem e os benefícios à sociedade sejam aumentados (JOHNSON apud CARROLL, 1999).

Atualmente, acredita-se que as empresas percebidas como responsáveis socialmente devam gozar de vantagens sobre aquelas que não estimulam essa percepção, tal como a atração de investidores em razão da perspectiva de lucro sustentável a longo prazo (JULIANI, 2002).

Inclusive, foi constatado que existe correlação positiva entre comportamento social e ambiental de empresas e resultados financeiros (JULIANI, 2002). Cumpre observar, no entanto, que a existência de correlação positiva entre duas variáveis não implica, necessariamente, relação de causa e efeito. Assim sendo, não há garantias de que a responsabilidade social afeta os resultados financeiros das empresas.

Uma evidência do crescimento da RSE é o fato de que o Instituto Ethos - entidade privada não lucrativa que congrega empresas socialmente responsáveis -, fundado em junho de 1998 com apenas 11 empresas associadas, possuía, após quatro anos de existência, 600 empresas associadas e, em setembro de 2010 possui 1.373 empresas (ÉBOLI, 2002; INSTITUTO ETHOS, 2010a).

A associação ao Instituto denota interesse pela questão ou, ao menos, o reconhecimento de que a RSE pode ter algum tipo de impacto sobre as empresas, uma vez que ele tem por missão "Mobilizar, sensibilizar e ajudar as empresas a gerir seus negócios de forma socialmente responsável, tornando-as parceiras na construção de uma sociedade sustentável e justa." (INSTITTUTO ETHOS, 2010b).

Além disso, a empresa associada deve cumprir os seguintes compromissos (EMPRESAS ASSOCIADAS, 2010b):

1. Divulgar em seus meios de comunicação corporativa o conceito de responsabilidade social empresarial, conforme o conceito do Instituto Ethos, junto aos públicos com os quais interage (acionistas, colaboradores, consumidores, fornecedores, comunidades e governos).

2. Comprometer-se com o tema e buscar progressivamente a excelência em políticas e práticas de responsabilidade social.

3. Participar de atividades e eventos promovidos pelo Instituto Ethos, tais como fóruns, reuniões, palestras e debates, que possuem o objetivo de incorporar a RSE ao negócio.

Uma possível explicação para este fato é que os consumidores estão demandando produtos consistentes com valores sociais. Assim, as empresas veem na responsabilidade social a possibilidade de criar estratégias que contribuam para a sua boa imagem, pois o desempenho econômico é função da vantagem competitiva que, por sua vez, é criada e sustentada por uma série de fatores, inclusive a satisfação dos consumidores e a percepção da sociedade em relação à empresa (BORGER, 2001; MELO NETO; FROES, 1999).

À medida que os produtos, serviços e marcas ganham maior visibilidade, aceitação e potencialidade, a responsabilidade social pode contribuir de forma decisiva para a sustentabilidade e o desempenho empresarial (MELO NETO; FROES, 1999). Segundo alguns autores, o retorno do investimento em responsabilidade social ocorre quando os consumidores da empresa privilegiam as suas atitudes e reconhecem o seu desempenho (MELO NETO; FROES, 1999). Para os mesmos autores, como consequência,

[...] a empresa vira notícia, potencializa a sua marca, reforça a sua imagem, assegura a lealdade de seus empregados, fideliza clientes, reforça laços com parceiros, conquista novos clientes, aumenta sua participação no mercado, conquista novos mercados e incrementa suas vendas. (MELO NETO; FROES, 1999, p. 162).

Segundo Borger (2001, p. 26),

[...] uma reputação corporativa superior é um bem intangível e uma fonte de vantagem estratégica, aumentando a capacidade de uma corporação de 
criar valor no longo prazo, sendo uma contribuição para a performance global das empresas.

Ainda, de acordo com a mesma autora,

[...] os investidores estão mais propensos a investir em empresas que usufruem uma reputação superior devido aos menores riscos percebidos e potencialmente maiores oportunidades de marketing. (BORGER, 2001, p. 26).

De acordo com Fischer (2002, p. 77),

[...] o diferencial de 'empresa focada no social' popularizou-se, tornando-se essencial à formação de uma imagem institucional positiva e empática.

Por outro lado, a busca de retorno em termos de imagem e de comportamento favorável do consumidor em relação à empresa reside na necessidade de recursos para serem investidos em ações sociais. No entanto, algumas considerações devem ser realizadas pelas empresas em relação à sua adequação às ações sociais, a fim de que possam obter o retorno esperado.

A carência social, a população objeto desta carência, o serviço social básico associado a esta carência e as características da população-alvo são elementos definidores dos projetos sociais. (MELO NETO; FROES, 1999, p. 34-35).

Segundo Bloom et al. (2006), algumas questões importantes devem ser trabalhadas, a fim de que o investimento em ações sociais possa propiciar o retorno esperado, quais sejam:

- Há um número suficiente de consumidores que possui afinidade com a causa?

- Os consumidores acreditam na real vinculação e comprometimento da marca com a causa?

- A marca diferencia-se das demais, à vista dos consumidores, em razão da vinculação à causa?

- Quanto à vinculação a uma causa é mais contributivo para potencializar os resultados, comparado a outras possíveis iniciativas?

Em outra abordagem da questão, Ashley (2002) afirma que

[...] o posicionamento de cada empresa estará associado ao perfil cultural dos públicos que efetivamente exercem poder sobre a direção dela, e esse perfil se reflete na orientação quanto a sua responsabilidade social.

Assim, observa-se que, em termos estratégicos, faz-se importante que a causa social para a qual uma empresa contribui possua afinidade com o seu negócio, a fim de que os públicos desenvolvam associações positivas e comportamentos que privilegiem estas empresas e seus produtos.

\section{$3 \mathrm{O}$ consumidor frente à responsabilidade social empresarial}

Do ponto de vista empresarial, os investimentos em ações sociais tornam-se atrativos enquanto oportunidade, à medida que esses elementos proporcionam algum tipo de distinção ou de vantagem competitiva. Para tanto, os consumidores devem perceber a relevância desses esforços e sentirem-se atraídos pelas ofertas realizadas por estas empresas. A razão fundamental para o consumidor adotar este comportamento reside no suposto interesse e na percepção que ele tem de contribuir, ainda que indiretamente, a causas sociais.

Osterhus (1997) acredita que as estratégias e ações sociais podem proporcionar vantagem competitiva às empresas, mas que para tanto é mister a necessidade de esforços no sentido de fazer com que as atitudes dos consumidores efetivem-se em comportamento, o que permitiria reduzir os riscos inerentes à iniciativa.

Nesta linha, alguns autores afirmam que a RSE é importante por influenciar a opinião dos consumidores sobre as empresas, e assim afetar a opinião sobre os seus produtos (BROWN; DACIN, 1997). Assim, é o conhecimento que os consumidores têm e as associações que eles fazem com produtos e empresas que podem proporcionar vantagem competitiva (BROWN; DACIN, 1997).

Diversos trabalhos apontam a existência de relacionamento entre o comportamento do consumidor e a RSE.

Com base em uma pesquisa realizada em Atlanta junto a 44 pessoas ( 22 homens e 22 mulheres) entre 25 e 36 anos de idade, de diversas classes sociais e níveis de escolaridade, por meio de entrevistas em profundidade, Mohr, Webb e Harris (2001) concluíram haver impacto da RSE sobre o comportamento do consumidor, uma vez que deles, 11 pensavam em levar em consideração a RSE em suas decisões de compra; 8 a levavam em consideração em algumas de suas compras; e 9 baseavam muitas das suas compras na RSE. Ademais, estes mesmos autores afirmam que o volume de livros vendidos sobre o assunto e a quantidade de recursos investidos em fundos financeiros que investem em empresas socialmente responsáveis evidenciam o interesse dos consumidores sobre o tema (MOHR; WEBB; HARRIS, 2001).

Uma pesquisa realizada em 1.037 lares norteamericanos estatisticamente selecionados para representar todos os Estados Unidos, ao longo de seis meses, cujo objetivo foi identificar a influência da RSE, permitiu concluir que a performance social da empresa afeta significativamente o consumidor, os empregados e os investidores em suas decisões em relação à empresa (GILDEA, 1995). A mesma pesquisa apontou que $88 \%$ dos consumidores entrevistados disseram preferir comprar de uma empresa socialmente responsável, e $92 \%$ declararam-se menos propensos 
a comprar de empresas que não são socialmente responsáveis (GILDEA, 1995).

Um fato que denota a preocupação das empresas em relação à RSE foi constatado com base em uma pesquisa realizada pelo IPEA (Instituto de Pesquisa Econômica Aplicada), que revelou que, em 2001, cerca de dois terços das empresas das regiões Sudeste e Nordeste realizaram investimentos sociais, totalizando R $\$ 4,15$ bilhões - cerca de $30 \%$ dos recursos empregados pelo governo federal na área social da região (MAGNAVITA, 2002). O mesmo estudo evidenciou, ainda, que este comportamento das empresas melhora a sua relação com os seus parceiros, governos e agências internacionais, e a sua imagem perante os consumidores e a comunidade (MAGNAVITA, 2002).

Uma pesquisa encomendada pelo Instituto Akatu sobre o consumidor brasileiro revelou que a decisão de compra de $49 \%$ dos entrevistados sempre se baseia em qualidade, $46 \%$ em preço, $28 \%$ em meio ambiente e $14 \%$ em moda, consideradas as categorias alimentos, produtos de higiene pessoal, roupas e eletroeletrônicos. A mesma pesquisa apresentou que 66\% dos entrevistados consideram importantíssimo para o mundo melhorar a saúde da população; 64\%, reduzir o desemprego; $61 \%$, reduzir a poluição; $56 \%$, diminuir as diferenças entre ricos e pobres; e 49\%, reduzir o trabalho infantil (INSTITUTO AKATU, 2002).

Uma pesquisa realizada pela Market Analysis Brasil em associação com a empresa canadense Globescan, por iniciativa do Instituto Akatu e do Instituto Ethos, com 800 consumidores, entre 16 e 69 anos de idade, nas cidades de São Paulo, Rio de Janeiro, Belo Horizonte, Porto Alegre, Curitiba, Salvador, Recife e Brasília que teve por objetivo conhecer a percepção dos consumidores quanto à RSE, aponta os seguintes dados (INSTITUTO ETHOS, 2008):

- $77 \%$ dos entrevistados declaram ter muito interesse em saber como as empresas tentam ser socialmente responsáveis;

- $51 \%$ do público em geral atribui um papel para as empresas que vai além do meramente econômico;

- $65 \%$ considera que as grandes empresas possuem responsabilidade de ajudar a resolver problemas sociais;

- Saúde e educação são os principais temas apontados como os que as empresas deveriam ajudar a resolver, com $28 \%$ e $22 \%$, respectivamente;

- $75 \%$ da população concorda que "como consumidor, posso interferir na maneira como uma empresa atua de forma responsável";

- $30 \%$ buscaram informações sobre a RSE;

- $26 \%$ ouviram ou leram sobre iniciativas de RSE;
- $12 \%$ premiaram empresas comprando seus produtos ou falando bem delas a outras pessoas, devido às suas ações de SER;

- $35 \%$ dos líderes de opinião declaram ter "premiado" ou "pensado em premiar" empresas por motivos ligados positivamente à sua responsabilidade social, contra

- $24 \%$ da média da população como um todo;

- $34 \%$ dos consumidores de países desenvolvidos premiaram empresas devido ao exercício da RSE, frente a $21 \%$ dos de países em desenvolvimento e a $12 \%$ dos do Brasil.

Ao realizarem uma pesquisa com consumidores de empresas de telefonia móvel na Europa, Salmones, Crespo e Bosque (2005) concluíram que a RSE possui uma importância significativa na avaliação geral do serviço, o que, por sua vez, possui uma importância ainda maior com a lealdade do cliente.

Manaktola e Jauhari (2007), ao estudarem a atitude de consumidores de hospedagem na Índia, concluíram que eles valorizam práticas que contribuam para a preservação do meio ambiente, e que os hotéis que realizam essas ações são preferidos em relação aos demais. No entanto, observou-se que os consumidores não estão dispostos a pagarem mais pelos serviços que estejam relacionados a essas causas (MANAKTOLA; JAUHARI, 2007).

Um estudo realizado por Bloom et al. (2006) apontou que as iniciativas de marketing societal, ou seja, aquelas que têm como objeto causas sociais, são capazes de contribuir para a formação de atitude dos consumidores em relação às marcas.

Marin, Ruiz e Rubio (2009) corroboram este pensamento, a partir de uma pesquisa realizada que teve por objetivo levantar e dimensionar as variáveis antecedentes e consequentes da contribuição da RSE sobre a fidelização dos consumidores, uma vez que, não obstante diversos trabalhos apontem tal relação, as ações sociais são apontadas, em outros trabalhos, como menos importantes do que outras tradicionais quando da decisão de compra, conforme já explicitado. Os resultados apontaram que de fato as ações de responsabilidade social estão ligadas à fidelidade pelo fato de que o consumidor desenvolve uma avaliação positiva da empresa que a realiza/ patrocina, à medida que se identifica com ela, e que salientar esta identidade social do consumidor é importante para estimular esta relação (MARIN; RUIZ; RUBIO, 2009).

De uma forma geral, os resultados das diversas pesquisas apresentadas apontam que os consumidores possuem interesse e valorizam as ações de RSE. No entanto, Brown e Dacin (1997) chamam a atenção para o fato de que, embora diversos estudos tenham evidenciado que o conhecimento do consumidor a respeito das empresas pode influenciar o seu 
comportamento em relação aos seus produtos, as habilidades corporativas mostraram-se mais significativas do que a responsabilidade social. Ademais, alguns autores reforçam que os consumidores devem se tornar conscientes para que a RSE possa impactar as suas decisões de compra (MOHR; WEBB; HARRIS, 2001). Mas o conhecimento dos consumidores sobre o assunto pode ser pequeno, em razão das dificuldades de eles obterem informações de diversas empresas para utilizarem no momento da compra (MOHR; WEBB; HARRIS, 2001).

Um estudo realizado por Singh, Sanchez e del Bosque (2008), que tinha por objetivo identificar a percepção de consumidores de duas diferentes localidades (Espanha e Reino Unido) com relação ao grau de importância dado à RSE e o impacto dela na percepção sobre a empresa, teve como principal resultado a fraca influência da comunicação acerca das ações de responsabilidade sobre os consumidores, e recomenda que as associações sejam reforçadas. Assim, a falha na comunicação e no conhecimento do consumidor podem ser inibidores da sua resposta em relação à RSE, o que, por sua vez, dificulta que as empresas obtenham retornos financeiros, de melhoria da imagem e de outras naturezas com tais iniciativas.

Em vista dos diversos resultados das pesquisas supra-apresentadas e dos objetivos deste trabalho, foi realizada uma pesquisa de campo com a finalidade de se verificar se a RSE é um fator importante na decisão de compra e se as ações e causas sociais realizadas e apoiadas por empresas são conhecidas. Assim, a seguir, apresenta-se a metodologia da pesquisa de campo, os seus resultados e as conclusões do trabalho.

\section{Metodologia da pesquisa de campo}

A pesquisa de campo teve por objetivo detectar a importância das ações sociais realizadas/patrocinadas por empresas nas decisões de compra do consumidor. Para tanto, foi realizada em duas etapas, a saber: a primeira, teve objetivo exploratório por concentrar-se no levantamento de aspectos importantes para a tomada de decisão de compra; a segunda teve objetivo conclusivo descritivo, por concentrar-se no dimensionamento da importância de cada fator levantado na etapa anterior (MATTAR, 2006; VERGARA, 2009).

A população pesquisada foi a de pós-graduandos de uma universidade paulista, composta de 300 pessoas. As marcas e categorias de produtos escolhidas foram as do tipo de conveniência, do gênero alimentício, que têm se destacado em sucessivas pesquisas periódicas de Top of mind, realizadas pelo Datafolha e publicadas pelo jornal Folha de São Paulo. Esta escolha deu-se pelo fato de que, por definição, os produtos de conveniência são comprados com maior frequência, e de que os produtos mais lembrados possuem maior chance de serem conhecidos de maneira mais profunda. Além disso, buscou-se evitar a escolha de produtos que pudessem ter baixa frequência de compra, tal como produtos de limpeza por parte dos homens.

A etapa exploratória foi realizada por meio de dois grupos de foco, com 10 pessoas cada, pertencente à população de interesse. Teve por objetivo levantar os principais fatores que influenciam a decisão de compra de produtos de consumo, a fim de se obter maior foco e eficácia na etapa quantitativa. Para tanto, foi utilizado um roteiro semiestruturado baseado na revisão da literatura apresentada, a fim de conduzir a discussão - o que foi feito pelo próprio pesquisador. Os fatores considerados tiveram por base uma análise de conteúdo dos dados coletados junto aos grupos, os quais foram gravados, com conhecimento dos pesquisados (BARDIN, 2004). Assim, foram considerados os seguintes fatores: preço, qualidade, opinião de outras pessoas, marca e sabor A responsabilidade social, embora não tenha sido um dos fatores apontados, foi incluída na pesquisa quantitativa, uma vez que este trabalho visa concluir não apenas se a RSE é ou não importante nas decisões de compra, mas também o quão importante ela é frente a outros fatores.

A etapa conclusiva descritiva consistiu em um levantamento junto a 60 pessoas da população definida, entre os meses de junho e julho de 2009 , o que representa $20 \%$ da população de 300 alunos, já excluídos os alunos que participaram da pesquisa exploratória. Escolheu-se este público em vista da acessibilidade por parte dos pesquisadores, e por eles se constituírem um grupo com alta escolaridade, acreditando-se que este fator seja um possível indicador de tendência, dada a sua característica de formador de opinião, conforme já apresentado na revisão da literatura. $\mathrm{O}$ tamanho da amostra foi definido de forma a permitir a utilização da estatística $X^{2}$, uma vez que pode ser considerada grande para as exigências da técnica utilizada (teste de Friedman) (SIEGEL, 1986).

Com base em um cadastro fornecido pela instituição, foi realizada uma amostragem probabilística com sorteio aleatório dos participantes da pesquisa. Após consulta aos alunos sorteados por meio telefônico, para confirmação de sua aquiescência em colaborar com este levantamento, foram remetidos por $e$-mail questionários de autopreenchimento, os quais foram posteriormente recebidos também por e-mail. Juntamente com o questionário foi encaminhada uma carta de apresentação que esclarecia os objetivos da pesquisa - o que já havia sido mencionado quando da confirmação da concordância em participar da pesquisa. Aqueles que não concordaram em participar da pesquisa, quando da consulta acerca da sua concordância (8 alunos) foram substituídos por outros, também sorteados, visando garantir a preservação da aleatoriedade e do tamanho da amostra. 
A primeira versão do questionário foi submetida a dois pré-testes, tendo sido realizadas adequações até que se chegasse à versão final. No questionário foi apresentada a definição de responsabilidade social exposta na introdução deste trabalho, de forma que os respondentes partissem de uma base comum de conhecimento acerca do assunto.

$\mathrm{O}$ instrumento de coleta era dividido em duas partes: a primeira apresentava um quadro que continha diversas categorias de produtos, juntamente com uma relação de fatores aos quais o respondente deveria atribuir uma nota de 1 a 10, conforme o respectivo grau de influência sobre a sua decisão de compra. Quanto maior a nota atribuída, mais representativo seria o fator, ao pesquisado, em termos de contribuição para a decisão de compra de uma determinada categoria de produto; a segunda parte questionava o conhecimento do pesquisado acerca das ações sociais vinculadas às marcas consideradas e/ou às suas fabricantes. Assim, apresentava as mesmas categorias exibidas no primeiro quadro, e era solicitado que o respondente assinalasse se cada uma das marcas bem como as suas respectivas fabricantes realizavam ou não ações de responsabilidade social. Havia a prerrogativa da resposta não sei no caso de o entrevistado não estar apto a responder tal questão, evitando a criação de viés. No caso de afirmarem que realizavam ações sociais, era necessário que fossem especificadas, a fim de se verificar a aderência com a realidade, a qual foi levantada por meio de uma pesquisa em fonte secundária, oficial de cada empresa.

\section{Apresentação e análise dos resultados}

Dos 60 alunos pesquisados, 25 eram mulheres e 35 eram homens, e a amplitude da idade foi de 23 a 62 anos, guardando aderência ao perfil da população. No entanto, em vista dos objetivos da pesquisa, e pelo fato de se considerar que a escolaridade era um melhor indicador de compreensão e ciência das ações sociais realizadas ou patrocinadas por empresas, conforme apontado na literatura, não se buscou averiguar associações com gênero ou idade.
A seguir são apresentadas na Tabela 1 as médias do grau de influência na decisão de compra de cada variável questionada para cada uma das categorias de produtos consideradas.

A fim de que se pudesse extrair conclusões corretas acerca dos dados apresentados, realizou-se o teste não paramétrico de Friedman, com nível de significância de 0,05 , que permite averiguar se as médias das variáveis consideradas são diferentes para cada categoria de produtos considerada (SIEGEL, 1986; PESTANA; GAGEIRO, 2001). Utilizou-se o software SPSS versão 16.0 para a realização do teste.

Cabe ressaltar que os testes não paramétricos se constituem em uma boa opção de análise estatística aos dados das ciências do comportamento por apresentarem uma série de vantagens em relação aos testes paramétricos, entre elas o fato de não haver necessidade de se realizarem suposições sobre a população e a aplicabilidade a pequenas amostras (SIEGEL, 1986).

O resultado do teste $\left(X^{2}=32,54\right.$ com cinco graus de liberdade) apresentou um nível de significância associado de 0,000. Assim, sendo o nível de significância 0,05 , definido a priori, superior ao obtido com o teste, rejeita-se Ho. Desta forma, conclui-se que as médias dos fatores considerados são significantemente diferentes.

Muito embora possa ser evidente quais são as variáveis mais levadas em consideração, em razão das médias obtidas, realizou-se uma comparação duas a duas a fim de se verificar quais são aquelas mais significativas. Foram considerados diferentes os pares em que se pôde aferir a seguinte desigualdade (PESTANA; GAGEIRO, 2001) (Equação 1):

$$
\begin{aligned}
& |\mathrm{Rp}-\mathrm{Rq}|>\mathrm{t}_{1}- \\
& -\alpha / 2 \sqrt{2 n(A-B) /(n-1)(k-1)}
\end{aligned}
$$

em que: $\mathrm{t}_{1}-\alpha / 2$ é o quartil de ordem $1-\alpha / 2$ da distribuição t de Student com (n-1)(k-1) graus de liberdade, e $B=\frac{A}{n}$ e $A=\frac{n k(k+1)(2 k+1)}{6}$.

Tabela 1. Média da importância dos fatores considerados quando da decisão de compra.

\begin{tabular}{lcccccc}
\hline \multirow{2}{*}{ Categoria } & \multicolumn{7}{c}{ Fatores } \\
\cline { 2 - 7 } & Preço & Qualidade & $\begin{array}{c}\text { Opinião de } \\
\text { outras pessoas }\end{array}$ & Marca & $\begin{array}{c}\text { Responsabilidade } \\
\text { social da marca/empresa }\end{array}$ & Sabor \\
\hline Cerveja & 6,3 & 8,2 & 3,7 & 6,8 & 2,6 & 8,9 \\
Chocolate & 6,5 & 9,1 & 3,3 & 7,0 & 3,0 & 9,3 \\
Leite & 6,8 & 9,1 & 3,0 & 6,0 & 3,1 & 7,7 \\
Maionese & 6,3 & 8,5 & 3,1 & 6,1 & 2,7 & 7,6 \\
Margarina & 6,5 & 8,5 & 2,8 & 6,1 & 2,7 & 7,9 \\
Refrigerante & 5,8 & 8,0 & 2,6 & 7,6 & 3,1 & 8,8 \\
Sorvete & 5,8 & 8,8 & 2,8 & 7,1 & 2,8 & 9,3 \\
Média das médias & 6,3 & 8,6 & 3,1 & 6,7 & 2,8 & 8,5 \\
\hline
\end{tabular}


A partir dos cálculos dos pares, comparados com o valor crítico encontrado $(32,54)$, observou-se que o fator qualidade é superior ao fator opinião dos outros e ao fator responsabilidade social em termos da média de importância, e que o fator sabor também é superior aos fatores opinião dos outros e responsabilidade social. Observou-se, ainda, que os fatores preço e marca apresentam igualdade, assim como os fatores qualidade e sabor.

Em vista dos resultados obtidos, observa-se que a qualidade e o sabor das categorias de produtos apresentam-se como mais importantes para os pesquisados do que os outros fatores considerados. Este resultado indica que a satisfação pessoal possui maior importância nas decisões em relação a outros fatores para este público, ao menos quando da compra das categorias de produtos consideradas.
Assim, a responsabilidade social apresenta a média geral mais baixa de todos os fatores considerados, o que sinaliza que as preocupações dos pesquisados não levam significativamente em consideração este fator, comparado com os demais considerados.

Dos 60 pesquisados, apenas sete pessoas mencionaram ações sociais condizentes com o que as empresas ou marcas efetivamente realizam. Todas as outras 53 pessoas pesquisadas declararam desconhecer se as marcas consideradas ou seus respectivos fabricantes realizavam ações de responsabilidade social, ou afirmaram conhecer, mas não souberam dizer quais ações realizavam ou que causas apoiavam.

No Quadro 1, são apresentadas as categorias e marcas consideradas, o seu fabricante, as principais ações e causas sociais que empreendem ou apoiam, além do número de respondentes que apresentou

Quadro 1. Conhecimento das ações realizadas pelas marcas e empresas consideradas.

\begin{tabular}{|c|c|c|c|c|}
\hline Categoria & Marca & Fabricante & Ações sociais que realiza & $\begin{array}{c}\text { Número de citações } \\
\text { dos entrevistados com } \\
\text { conhecimento }\end{array}$ \\
\hline \multirow[t]{3}{*}{ Cerveja } & Skol & Ambev & Meio ambiente e assistência social & 1 \\
\hline & Antarctica & Ambev & Meio ambiente e assistência social & 1 \\
\hline & Brahma & Ambev & Meio ambiente e assistência social & 1 \\
\hline \multirow[t]{3}{*}{ Chocolate } & Nestlé & Nestlé & $\begin{array}{l}\text { Educação, saúde, cultura, meio } \\
\text { ambiente e assistência social }\end{array}$ & 5 \\
\hline & Garoto & Nestlé & $\begin{array}{l}\text { Educação, saúde, cultura, meio } \\
\text { ambiente e assistência social }\end{array}$ & 1 \\
\hline & Lacta & Kraft & $\begin{array}{l}\text { Educação, saúde, cultura, meio } \\
\text { ambiente e assistência social }\end{array}$ & - \\
\hline \multirow[t]{3}{*}{ Leite } & Parmalat & Parmalat & Saúde e educação & 1 \\
\hline & Ninho & Nestlé & $\begin{array}{l}\text { Educação, saúde, cultura, meio } \\
\text { ambiente e assistência social }\end{array}$ & 2 \\
\hline & Itambé & Itambé & Saúde e meio ambiente & - \\
\hline \multirow[t]{3}{*}{ Maionese } & Hellmann's & Unilever & $\begin{array}{l}\text { Educação, saúde, meio ambiente, } \\
\text { assistência social }\end{array}$ & - \\
\hline & Arisco & Unilever & $\begin{array}{l}\text { Educação, saúde, meio ambiente, } \\
\text { empregabilidade de deficientes }\end{array}$ & - \\
\hline & Gourmet & Unilever & $\begin{array}{l}\text { Educação, saúde, meio ambiente, } \\
\text { empregabilidade de deficientes }\end{array}$ & - \\
\hline \multirow[t]{3}{*}{ Margarina } & Doriana & Unilever & $\begin{array}{l}\text { Educação, saúde, meio ambiente, } \\
\text { empregabilidade de deficientes }\end{array}$ & - \\
\hline & Primor & Bunge & Educação e cultura & - \\
\hline & Delícia & Bunge & Educação e cultura & - \\
\hline \multirow[t]{3}{*}{ Refrigerante } & Coca-cola & Coca-cola & $\begin{array}{l}\text { Saúde, educação, meio ambiente, } \\
\text { esporte, cultura e assistência social }\end{array}$ & 2 \\
\hline & Antarctica & Ambev & $\begin{array}{l}\text { Saúde, educação, meio ambiente, } \\
\text { esporte, cultura e assistência social }\end{array}$ & 1 \\
\hline & Fanta & Coca cola & $\begin{array}{l}\text { Saúde, educação, meio ambiente, } \\
\text { esporte, cultura e assistência social }\end{array}$ & - \\
\hline Sorvete & Kibon & Unilever & $\begin{array}{l}\text { Educação, saúde, meio ambiente, } \\
\text { empregabilidade de deficientes }\end{array}$ & - \\
\hline
\end{tabular}

Fonte: Páginas das empresas na internet (www.ambev.com.br; www.nestle.com.br, www.parmalat.com.br, www.unilever.com.br, www.bunge.com.br, www.cocacola.com.br, www.kraft.com.br, www.itambe.com.br ). Data de acesso: 03/04/2009. 
conhecimento condizente. Observa-se que as 19 marcas consideradas na pesquisa são fabricadas por oito empresas.

Assim, a fim de se verificar se o conhecimento das ações possui relação com o grau de valorização deste fator nas decisões de compra, foi realizado o teste Mann-Whittney, que permitiu verificar se as médias do fator eram iguais (H0) ou diferentes entre os grupos que conheciam (sete pessoas) e que desconheciam (53 pessoas).

O teste Mann-Whitney apresentou um nível de significância unicaudal associado de 0,000 . Assim, sendo o nível de significância 0,05 , definido a priori, superior ao obtido com o teste, rejeita-se Ho. Desta forma, conclui-se que as médias dos fatores considerados são significantemente diferentes, e que a média do grupo que efetivamente conhece as ações de responsabilidade social realizadas ou apoiadas pelas empresas consideradas é maior do que a do grupo que não as conhecem.

Em razão do pequeno número de entrevistados com conhecimento sobre estas ações, pode-se concluir que a comunicação destas empresas, de uma forma geral, não é eficaz em transmitir tais informações - o que certamente se coloca como empecilho na criação de interesse e na valorização da questão, por parte do consumidor.

Analisando-se conjuntamente a Tabela 1 e o Quadro 1, pode-se cogitar como explicação para a pequena importância da RSE nas decisões de compra das categorias de produtos consideradas o fato de as pessoas desconhecerem as ações dessa natureza empreendidas pelas marcas e pelos seus fabricantes. Tal desconhecimento não seria esperado no caso de pessoas mais escolarizadas, como as focalizadas neste estudo.

\section{Conclusões}

A RSE pode ser utilizada, por um lado, como um caminho para a construção de uma sociedade melhor e mais justa e, por outro, como uma estratégia que pode proporcionar vantagem competitiva.

Embora Jones, Comfort e Hilliard (2007) e Castaldo et al. (2009), entre outros autores apresentados na revisão da literatura, afirmem e discorram sobre a relevância da realização de ações sociais para a melhoria dos resultados das empresas, a pesquisa de campo realizada evidenciou que os consumidores valorizam pouco essa questão, comparativamente a outros fatores, tais como qualidade e preço, conforme apontaram Marin, Ruiz e Rubio (2009).

Portanto, contrapondo-se aos diversos estudos e afirmações realizadas por outros autores, a pesquisa apresentada neste artigo sinalizou que a responsabilidade social é um fator com pouca importância sobre a decisão de compra, quando comparado a outros fatores, apesar de outras pesquisas apontarem a disposição e interesse do consumidor em relação ao assunto.

A pesquisa também evidenciou que as empresas não vinculam as suas marcas a temas e ações sociais, ao menos na intensidade necessária para que os consumidores conheçam e lembrem-se disso, muito embora as marcas estejam mais próximas dos consumidores, em relação ao nome da empresa requerendo que esforços intensos e específicos sejam realizados, conforme defende Osterhus (1997).

Assim, parece um paradoxo deixar a responsabilidade social vinculada à empresa e não à marca, enquanto que esta última é que se vincula ao consumidor. Desta maneira, dificilmente os consumidores passarão a levar em consideração este fator de forma imperativa para a decisão de compra, não obstante ele seja reconhecido como um diferencial pelo qual eles se interessam.

A comunicação pelas empresas acerca das suas ações de responsabilidade social, implicando desconhecimento por parte dos consumidores, pode-se apresentar como inibidor do processo, pois se verificou que os consumidores as desconhecem, ao menos por meio das marcas, que são justamente os ícones que as aproximam do consumidor. A associação mais direta das ações empreendidas pelas empresas às suas marcas deve contribuir para que a disposição e interesse apresentado pelos consumidores transformem-se em comportamento que premie aquelas que buscam a melhoria da sociedade, conforme defendido por Brown e Dacin (1997).

A reputação é um ativo de imenso valor, resultado de uma mistura de comportamento, comunicação e expectativa (LEWIS, 2001). Evidencia-se, então, que, em termos estratégicos, não adianta somente a empresa empreender ou apoiar ações e programas sociais; ela deve prover os beneficiários destas ações e programas e, especialmente o seu público-alvo, de informações relativas às suas contribuições à sociedade.

Três limitações devem ser consideradas em relação ao presente trabalho: a primeira é o fato de que o comportamento de compra foi focalizado utilizando-se como base a associação dos consumidores de marcas com ações de responsabilidade social, de maneira direta, e com as empresas que as produzem, de maneira indireta, uma vez que elas não foram divulgadas; a segunda é o tamanho relativamente pequeno da amostra e a natureza específica do público pesquisado; a terceira é o tipo de produto pesquisado, para o qual talvez a RSE seja naturalmente menos importante para a decisão de compra do que os fatores mais relevantes apontados (sabor e qualidade).

Por fim, em vista da importância do tema RSE, tanto pelos impactos que estas ações podem causar à sociedade quanto pela ótica da vantagem competitiva, recomenda-se que outros estudos sejam realizados, com outros públicos e com outras categorias de 
produtos, e que associações possam ser efetivadas com variáveis relativas ao perfil socioeconômico, comportamental e psicográfico deles.

Também estudos comparativos que apresentem empresas que vêm obtendo e empresas que não vêm obtendo melhoria nos resultados em vista da realização/patrocínio de ações sociais, tendo como base o modelo de Bloon et al. (2006), podem contribuir para o aprofundamento da compreensão sobre a questão.

\section{Referências}

ASHLEY, P. A. (Coord.). Ética e responsabilidade social nos negócios. São Paulo: Saraiva, 2002.

BARDIN, L. Análise de conteúdo. Lisboa: Edições 70, 2004.

BLOOM, P. N. et al. How social-cause marketing affects consumer perceptions. MIT Sloan Management Review, v. 47, n. 2, p. 49-55, 2006.

BORGER, F. G. Responsabilidade social: efeitos da atuação social na dinâmica empresarial. 2001. Tese (Doutorado)-Faculdade de Economia, Administração e Contabilidade, Universidade de São Paulo, São Paulo, Brasil, 2001.

BROWN, T. J.; DACIN, P. A. The company and the product: corporate associations and consumer product response. Journal of Marketing, v. 61, p. 68-84, 1997.

CARROLL, A. B. Corporate social responsibility. Business Society, v. 38, n. 36, p. 268-295, 1999.

CASTALDO, S. et al. The missing link between corporate social responsibility and consumer trust: the case of fair trade products. Journal of Business Ethics, v. 84, n. 19, p. 1-15, 2009.

ÉBOLI, C. Cresce o interesse das empresas pelas ações de responsabilidade social. Relatório Gazeta Mercantil Terceiro Setor, São Paulo, 29 maio 2002. Disponível em: $<$ http://www.ethos.org.br/sistemas/empresas_entidades/ empresas_associadas/lista_geral/index.asp $>$. Acesso em: 23 set. 2010.

FISCHER, R. M. O desafio da colaboração: práticas de responsabilidade social entre empresas e terceiro setor. São Paulo: Gente, 2002.

FRIEDMAN, R. E. The social responsibility of business is to increase its profits. New York Times, New York, 13 set. 1970 .

GILDEA, R. L. Consumer survey confirms corporate social action affects buy. Public Relations Quarterly, Rhineback, v. 39, n. 4, p. 20-23, 1995.

INSTITUTO AKATU. O consumidor brasileiro e a construção do futuro. São Paulo, 2002. Disponível em: <http://www.akatu.org.br/akatu_acao/publicacoes/ responsabilidade-social-empresarial>. Acesso em: 28 set. 2010.

INSTITUTO ETHOS. Empresas associadas. 2010a. Disponível em: <http://www1.ethos.org.br/EthosWeb/ pt/1937/destaque_home/participe/empresas_associadas. aspx>. Acesso em: 23 set. 2010a.

INSTITUTO ETHOS. Termo de associação. Disponível em: $<$ http://www.ethos.org.br/sistemas/empresas_entidades/ empresas_associadas/cadnovo/cadastro.asp $>$. Acesso em: 23 set. 2010 b.

INSTITUTO ETHOS. Responsabilidade social das empresas: percepção do consumidor brasileiro. São Paulo, 2002.

JONES, P.; COMFORT, D.; HILLIARD, D. What's in store? Retail marketing and corporate social responsibility. Marketing Intelligence \& Planning, v. 25, n. 1, p. 17-30, 2007.

JULIANI, D. Investidor vê lucro no social. Relatório Gazeta Mercantil Terceiro Setor, São Paulo, 29 maio 2002.

LEWIS, S. Measuring corporate reputation. Corporate Communications, v. 6, n. 1, p. 31-35, 2001.

MAGNAVITA, M. O setor privado adere ao combate à pobreza. Relatório Gazeta Mercantil Terceiro Setor, São Paulo, 29 maio 2002.

MANAKTOLA, K.; JAUHARI, V. Exploring consumer attitude and behavior towards green practices in the lodging industry in India. International Journal of Contemporary Hospitality Management, v. 19, n. 5, p. 364-377, 2007.

MARIN, L.; RUIZ, S.; RUBIO, A. The role of identity salience in the effects of corporate social responsibility on consumer behavior. Journal of Business Ethics, v. 84, n. 1, p. 65-78, 2009.

MATTAR, F. N. Pesquisa de marketing. v. 2. São Paulo: Atlas, 1998.

MELO NETO, F. P.; FROES, C. Responsabilidade social \& cidadania empresarial. Rio de Janeiro: Qualitymark, 1999.

MOHR, L. A.; WEBB, D. J.; HARRIS, K. E. Do consumers expect companies to be socially responsible? The impact of corporate social responsibility on buying behavior. The Journal of Consumer Affairs, v. 35, n. 1, 2001.

OSTERHUS, T. L. Pro-social consumer influences estrategies: when and how do they work? Journal of Marketing, v. 61, p. 16-29, 1997.

PESTANA, M. H.; GAGEIRO, J. N. Análise de dados para ciências sociais. Lisboa: Sílabo, 2001.

SALMONES, M. M. G.; CRESPO, A. H.; BOSQUE, I. Rodríguez del. Influence of corporate social responsibility on loyalty and valuation of services. Journal of Business Ethics, v. 61, p. 369-385, 2005.

SIEGEL, S. Nonparametric statistics for the behavioral sciences. New York: McGraw-Hill, 1986.

SINGH, J.; SANCHEZ, M. M. G. S.; DEL BOSQUE, I. R. Understanding corporate social responsibility and product perceptions in consumer markets: a cross-cultural evaluation. Journal of Business Ethics, v. 80, n. 3, p. 597-611, 2008.

VALOR, C. Can consumers buy responsibly? Analysis and solutions for market falures. Journal of Consumer Policy, v. 31, n. 3, p. 315-326, 2008. 